ポーリングしたテルライトガラスの 2 次非線形光学効果とガラス構造

\author{
田中 勝久和, 鹿島 謙一内1, 梶原 浩一内1 \\ 平尾 一之的, 兽我 直弘的1，三戸 章裕的2 \\ 那須 弘行的3

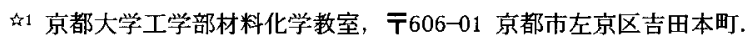 \\ 部 計量研究所熱物性部, テ 305 つくば市梅園1-1-4. \\ $\leadsto 3$ 三重大学工学部分子素材工学科, $\overline{\mathbf{T}} 514$ 津市上浜町 1515 .
}

\title{
Optical Second-order Nonlinearity and Glass Structure of Poled Tellurite Glasses
}

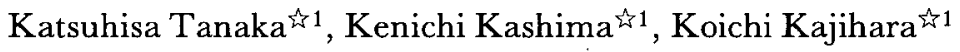 \\ Kazuyuki Hirao ${ }^{\hat{\imath} 1}$, Naohiro Soga $\hat{\imath} 1$ \\ Akihiro Mito ${ }^{\text {2 } 2}$ and Hiroyuki Nasu ${ }^{\text {\33 }}$ \\ 41 Division of Material Chemistry, Faculty of Engineering, Kyoto University, Yoshida-honmachi Sakyo-ku, \\ Kyoto 606-01. \\ \&2 National Research Laboratory of Metrology, Umesono, Tsukuba 905. \\ t3 Department of Chemistry for Materials, Faculty of Engineering, Mie University, Tsu 514.
}

Received August 25, 1994

\begin{abstract}
Glass transition temperature of $\mathrm{ZnO}-\mathrm{BaO}-\mathrm{TeO}_{2}$ glasses, which show optical second harmonic generation after the electrical poling, has been measured in order to discuss the relationship between second harmonic intensity and glass structure. The glass transition temperature decreases with a replacement of $\mathrm{BaO}$ by $\mathrm{ZnO}$, indicating that the flexibility of glass structure increases with an increase in the content of $\mathrm{ZnO}$. Hence, an orientation of ensemble of electric dipoles due to $\mathrm{TeO}_{4}$ trigonal bipyramid and $\mathrm{TeO}_{3}$ trigonal pyramid can take place more readily in the tellurite glass with high concentration of $\mathrm{ZnO}$, leading to the high optical second harmonic intensity and large second-order nonlinear coefficient in the glasses with $\mathrm{ZnO}$-rich composition. Furthermore, it is thought that preferential occurrence of electron polarization of $\mathrm{Ba}^{2+}$ hinders the orientation of tellurite structural units when the external electric field is applied. The very low second harmonic intensity of poled $15 \mathrm{PbO} \cdot 85 \mathrm{TeO}_{2}$ glass supports this speculation.
\end{abstract}

\section{1 緒言}

$\mathrm{Te}_{2}$ を構成単位の基本とするガラス，すなわちテル ライトガラスは, ガラス形成能, ガラス構造, および 種々の物理的性質に関して, きわめて興味深い挙動を 示す.Stanworth" が初めて明らかにしたように, 通常 の融液急冷法を用いた場合には， $\mathrm{Te}_{2}$ 単独ではガラス 化せず, 数mo1\%のアルカリ酸化物やアルカリ土類酸化 物などのいわゆる網目修飾酸化物を添加してはじめて
ガラスが生成する，超急冷法を用いれば， $\mathrm{Te}_{2}$ 単独で のガラス化が可能になる2).また，LiClやLiBrのよう なハロゲン化アルカリと $\mathrm{Te}_{2}$ の 2 成分系す容易にガラ ス化する3，4．このような観点加ら，Hf $2 \mathrm{n}_{2}$ のような 「強磁性寸前の金属 (nearly ferromagnetic metal)」 に準えて, $\mathrm{Te}_{2}$ 仗nearly network-forming oxide (網 目形成寸前の酸化物) とでも呼ばれるべき独特のガラ ス構成物質となっている。このガラスはその構造にお 
いても他の網目形成酸化物とは一線を画している。典 型的な網目形成酸化物である $\mathrm{Si}_{2}, \mathrm{~B}_{2} \mathrm{O}_{3}, \mathrm{GeO}_{2}$ などで はガラス網目の構成単位がS $\mathrm{S}_{0}$ 正四面体やBO 3 正三角形 など比較的高い対称性を有するのに対して，テルライ トガラスではTe04 三方両錐およびTe $0_{3}$ 三方錐といった 対称性の低い構造が単位となる においてTeはdsp ${ }^{3}$ 混成軌道を形成し，3つのエカトリ アル位置のうちの1つを非共有電子対が占める.

一方, テルライトガラスの電気的および光学的性質 に関してる興味深い報告がなされている。遷移金属酸 化物を含有するテルライトガラスは，同じ組成の他の 系のガラス，すなわち，ケイ酸塩，ホウ酸塩，リン酸 塩ガラスに比べて 3 桁程度高い電気伝導度を示す ${ }^{8-9)}$. また， $\mathrm{Li}^{+}$や $\mathrm{Ag}^{+}$を多量に含有するテルライトガラスで は高いイオン導電率が報告されている テルライトガラスは, 高い屈折率 ${ }^{2}$, 優れた赤外透過

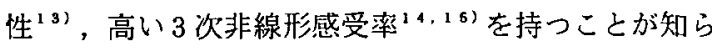
れている，最近著者らはポーリングを施した $\mathrm{Li}_{2} \mathrm{O}-\mathrm{Nb}_{2}$ $0_{5}-\mathrm{TeO}_{2}$ 系のテルライトガラスが 2 次非線形光学効果を 示すことを見いだしだる)。これにより，テルライトガ ラスに新たな興味深い物性が付け加えられたことにな ろ.

ところで, 酸化物ガラスにおける 2 次非線形光学効 果は，OsterbergとMargulis ${ }^{17}$ にり，Geをドープし たシリカガラスファイバーにおいて初めて見いだされ た、彼らの報告によると、Geドープシリカガラスファ イバーにNd:YAGレーザーの基本波である1064nmの光を 照射し続けたところ，第二高調波である532nmの光がガ ラスファイバ一から発生し始め, 約10時間後にその強 度が飽和した。 その後, Myersら ${ }^{(8)}$ は, 直流電場下で ポーリングされたバルクのシリカガラスにおいて第二 高調波発生が観察されることを報告した，元来，ガラ スは光学的等方体であり，巨視的に中心対称性を有し ていることから， 2 次非線形光学過程は禁制となるは

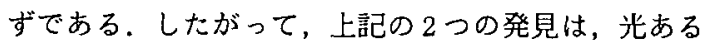
いは電場のような外部刺激によりガラス中に光学的異 方性が誘起されたことを示すむのであり，基礎的見地 からきわめて興味深い，また，実用的観点からむ，短 波長光の導波路としての応用が期待される。この現象 の機構に関しては, 光電界あるいは直流外部電場によ り永久電気双極子の長距離的な秩序配向が形成され， これが光学的異方性を生じさせ 2 次非線形光学効果を 引き起こすと考えられている。テルライトガラスに関 して言えば，この永久双極子の起源は，中心対称性を
欠く構造単位である $\mathrm{Te} 0_{4}$ 三方両雓および $\mathrm{Te}_{3}$ 三方錐で あると推测されている191. 著者らは最近, $\mathrm{ZnO}-\mathrm{TeO}_{2}$ ， $\mathrm{Ba} 0-\mathrm{Te}_{2}, \mathrm{WO}_{3}-\mathrm{Te}_{2}$ およびZn0-Ba0- $\mathrm{TeO}_{2}$ 系のテルライ トガラスを作製し，これらにポーリングを施したのち に第二高調波発生の観察を試みた ${ }^{201} . Z \mathrm{n} 0-\mathrm{Te} \mathrm{O}_{2}$ 系抢上 びW0 $0_{3}-\mathrm{Te}_{2}$ 系では第二高調波の発生が見られ，特に前 者ではZn0含有量の增加にとすない第二高調波强度が增 加した。また，Ba0を多く含有する組成のガラスでは第 二高調波の発生が見られず，これはポーリングの際に $\mathrm{Ba}^{2+}$ イオンの電子分極が優先的に起こるためであると 推測した。しかし，これらのガラス組成，ガラス構造 と 2 次非線形光学効果の大きさとの関係は十分に明ら かにされているとは言えない. 本研究では, 2n0-Ba0$\mathrm{Te}_{2}$ 系ガラスのガラス構造の柔軟性をガラス転移温度 の観点から検討し，ガラス構造と第二高調波強度およ び 2 次非線形感受率との関係を考察した。また，新た にPb0- $\mathrm{Te}_{2}$ 系ガラスを作製し, 電子分極の大きなイオ ンと 2 次非線形光学効果との関係を明らかにすること を試みた。

\section{2 実験}

$\mathrm{x} \ln 0 \cdot(35-\mathrm{x}) \mathrm{Ba} 0 \cdot 65 \mathrm{Te}_{2} \quad(\mathrm{x}=5$ - 35mol\%) および15Pb $0.85 \mathrm{Te}_{2}$ 組成のガラスを通常の融液急冷法を用いて作 製した。出発原料として $\mathrm{Zn} 0, \mathrm{BaCO}_{3}, \mathrm{~Pb} 0$ および $\mathrm{Te}_{2}$ を 用いた。これらの原料を目的の組成となるように混合 したのち, 白金坩堝を用いて, 空気中, $750 か ら 900^{\circ} \mathrm{C}$ で30分間溶融した．融液をステンレス鋼製の板上に流 し出し，鉄板で押さえることにより急冷した。得られ た試料がアモルファスであることを，CuK $\alpha$ 線を用いた 粉末X線回折により確認した。また，ガラス転移温度を 調べるために，粉末試料を用いて示差熱分析（DTA）を 行った。昇温速度は $10 \mathrm{~K} \cdot \mathrm{min}^{-1}$ とした。

$15 \mathrm{Pb0} 85 \mathrm{Te} 0_{2}$ ガラスに関しては，ポーリングを施し たのちに，第二高調波強度の测定を行った。バルクの ガラス試料を厚さが約 $1 \mathrm{~mm}$ となるように研磨したのち， ステンレス鋼製の電極で挟み，電気炉中に設置した。 試料を昇温したのち外部から直流電場を加え，30分間 放置した。 その後，電場を印加したまま試料を冷却し， 試料の温度が室温まで下がったのちに電極を取り外し た。ポーリングの条件は $3 \mathrm{kV}, 250^{\circ} \mathrm{C}$ した。このよう にして得られた試料の 2 次非線形光学効果をMakerフリ ンジ法を用いて測定した。試料を回転台の上に取り付

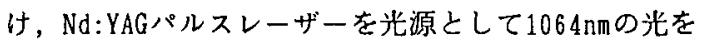
入射した，入射角を変化させながら，発生する532nmの 


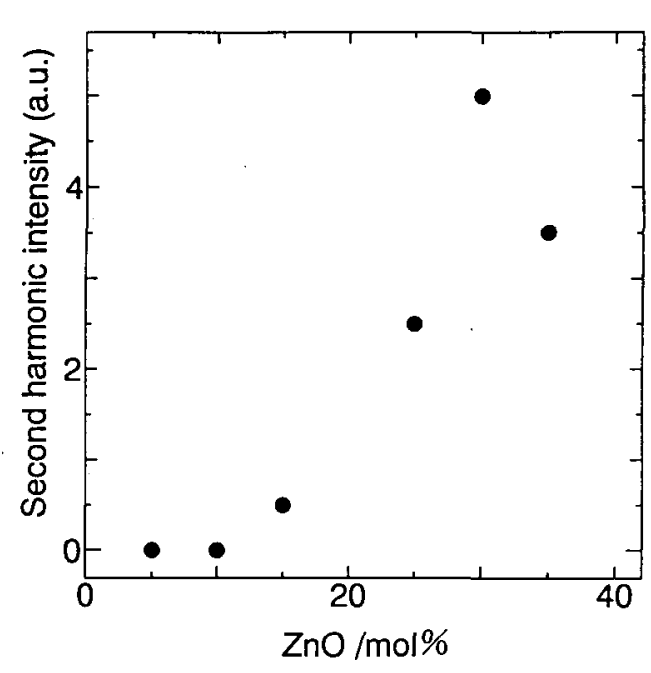

Fig. 1 Compositional dependence of second harmonic intensity for $\mathrm{ZnO}-\mathrm{BaO}-\mathrm{Te}_{2}$ system. ${ }^{20}$ ) The content of $\mathrm{TeO}_{2}$ is constant $(65 \mathrm{~mol} \%)$, and $\mathrm{BaO}$ is replaced by $\mathrm{ZnO}$. The poling was carried out at $280^{\circ} \mathrm{C}$ for $30 \mathrm{~min}$ under an applied dc electric field of $3 \mathrm{kV}$.

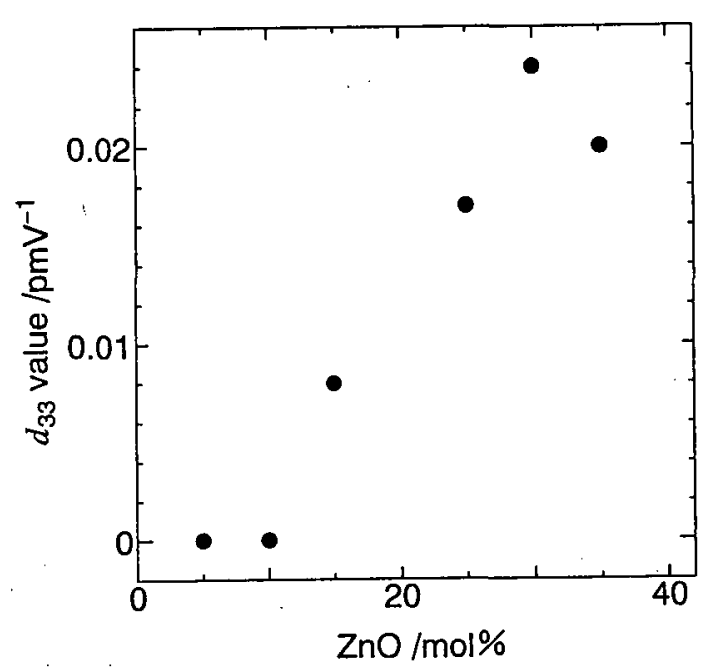

Fig. 2 Compositional dependence of second-order nonlinear coefficient, $\mathrm{d}_{33}$, for $\mathrm{ZnO} 0-\mathrm{BaO}-\mathrm{TeO}_{2}$ system. ${ }^{20}$ The content of $\mathrm{Te}_{2}$ is constant (65mol\%), and $\mathrm{BaO}$ is replaced by $\mathrm{ZnO}$. The poling was carried out at $280^{\circ} \mathrm{C}$ for $30 \mathrm{~min}$ under an applied dc electric field of $3 \mathrm{kV}$.
第二高調波を検出した。

\section{3 結果亡考察}

先に報告したように，Zn0-Ba0- $\mathrm{TeO}_{2}$ 系ガラスにおい て, Zn0含有量の多い組成のガラスからは第二高調波発 生が見られたが，Ba0含有量の多い組成のガラスでは第 二高調波発生が観察されなかった。 $\mathrm{ZnO} 0-\mathrm{Ba} 0-\mathrm{TeO}_{2}$ 系ガ ラスにおいて $\mathrm{Te}_{2}$ の含有量を一定 (65 mol\%) とし， $\mathrm{Zn}$ $0 と \mathrm{Ba} 0$ モル比を変化させた場合の第二高調波強度の 組成依存性をFig.1に示す ${ }^{20}$ ，また，第二高調波強度 加ら求められた 2 次非線形光学定数 $\mathrm{d}_{3}{ }_{3}$ の組成变化を.

Fig. 2に示す202。和3 の算出に際して，ポーリングした 平板状ガラスが平面に垂直な方向に一軸性の異方性を 有すると仮定し，電気双極子はisotropic systemで取 り扱えるとしだ"1).また，Kleinman対称性 ${ }^{22}$ が成り 立つと仮定した．このとき, 分極電場 $\mathrm{E}$ 関係は次 のようになる。

$$
\begin{aligned}
& P_{\mathrm{x}}=(2 / 3) d_{33} E_{\mathrm{z}} E_{\mathrm{x}} \\
& P_{\mathrm{y}}=(2 / 3) d_{33} E_{\mathrm{y}} E_{\mathrm{z}} \\
& P_{\mathrm{z}}=\left(d_{33} E_{\mathrm{x}}^{2}+d_{33} E_{\mathrm{y}}^{2}\right) / 3+d_{33} E_{\mathrm{z}}^{2}
\end{aligned}
$$

また, Makerフリンジパターン23) は以下の式で与えら れる24).

$$
\begin{aligned}
& P_{2 \omega}{ }^{\prime \prime}=\frac{C d^{2} t_{\omega}{ }^{\prime 4} T_{2 \omega}{ }^{\prime \prime} R(\theta) p^{2}(\theta) P_{\omega}{ }^{2} \sin ^{2} \Psi^{\prime}}{\left(n_{\omega}{ }^{2}-n_{2 \omega}{ }^{2}\right)^{2}} \\
& \Psi=(\pi L / 2)(4 / \lambda)\left(n_{\omega} \cos \theta_{\omega}{ }^{\prime}-n_{2 \omega} \cos \theta_{2 \omega}{ }^{\prime}\right)
\end{aligned}
$$

ここで $\mathrm{P}_{2} \omega$ "は第二高調波出力, $\mathrm{P} \omega$ は基本波入力, $\mathrm{d}$ は 2 次非線形光学定数， $\mathrm{n} \omega お よ ひ ゙ \mathrm{n}_{2} \omega$ は基本波おょび第二高 調波における屈折率， $\mathrm{t} \omega$ およよび $\mathrm{T} \omega^{\prime} \omega^{\prime \prime}$ は透過因子， $\mathrm{R}(\theta)$ は多重反射補正， $\mathrm{p}(\theta)$ は投影因子，Cはレーザーのビ 一ム径に依存する定数，以は試料の厚さ，入は基本波の 波長, $\theta \omega お よ ひ ゙ \theta_{2} \omega$ ”は基本波および第二高調波の屈 折角である。

今回作製した $\mathrm{Zn} 0-\mathrm{BaO}-\mathrm{Te}_{2}$ 系ガラスのガラス転移温 度の組成依存性をFig. 3に示す.Fig. 1およびFig. 2 上同 様, $\mathrm{TeO}_{2}$ の含有量を65mol\%で一定とし, $\mathrm{ZnO}$ とBa0のモ 


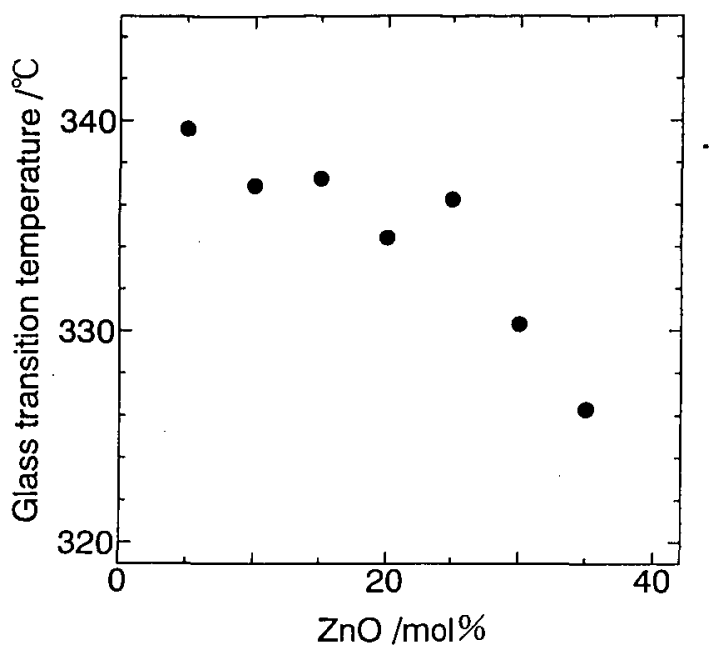

Fig. 3 Compositional dependence of glass transition temperature for the $\mathrm{ZnO}-\mathrm{BaO}-\mathrm{TeO}_{2}$ glass system. The content of $\mathrm{TeO}_{2}$ is constant (65mol\%). and $\mathrm{BaO}$ is replaced by $\mathrm{ZnO}$.

Table 1 Relative second harmonic intensity, IsH, of several poled binary tellurite glasses.

\begin{tabular}{ll}
\hline Glass system & $\mathrm{IsH}_{\mathrm{sH}}$ \\
\hline $\mathrm{PbO}-\mathrm{TeO}_{2}$ & $<0.5$ \\
$\mathrm{Ba} 0-\mathrm{TeO}_{2}$ & $\sim 0$ \\
$\mathrm{Li}_{2} \mathrm{O}-\mathrm{TeO}_{2}$ & $1 \sim 2$ \\
$\mathrm{ZnO} 0-\mathrm{TeO}_{2}$ & $2 \sim 10$ \\
$\mathrm{Nb}_{2} \mathrm{O}_{5}-\mathrm{TeO}_{2}$ & $2 \sim 3$ \\
$\mathrm{HO}_{3}-\mathrm{TeO}_{2}$ & $\sim 10$ \\
\hline
\end{tabular}

ル比を変化させている。ガラス転移温度は約 $320-340^{\circ} \mathrm{C}$ の乾囲にあり，Zn0含有量の增加にとむない単調に減少 している.このことは, ガラス構造がZnO濃度の増加に とすない柔軟性を增すことを示唆する。

さて，Fig. 1およびFig. 2より，第二高調波強度なら びに 2 次非線形光学定数 $\mathrm{d}_{33}$ はBa0含有量の多いガラス ではほぼゼロであり，Ba0のZn0による置換量が増える にしたがって単調に増加していることが分かる。この 系のガラスの構造は，これまで，IRやラマン分光法を 用いて調べられている25-27)。尾坂らはZnoやBaOなど
を含む 2 成分系のテルライトガラスのラマンスペクト ルを測定し， $\mathrm{TeO}_{4}$ 三方両錐および $\mathrm{TeO}_{3}$ 三方錐に対応す るバンドの面積強度を解析しだ）。 その結果， $\mathrm{Zn}^{2+}$ 。 $\mathrm{Ba}^{2+}$ のような網目修飾イオン濃度の增加にともない, 三方雨錐の割合は娍少し，逆に三方錐の割合が増加す ることが明らかとなっだら)。また，網目修飾イオンの 導入により非架橋酸素の生成が見られた。同様の解析 結果がSekiyaら ${ }^{271}$ によっても提出されている。また, 尾坂ら ${ }^{25)}$ による 三方錐と三方両錐の数の比の組成 依存性は， $\mathrm{ZnO} 0-\mathrm{TeO}_{2}$ と $\mathrm{BaO}-\mathrm{TeO}_{2}$ 系において相違が見ら れない，すなわち，組成が同じであれば，雨者のガラ スに含まれる三方錐と三方両錐との割合は互いに等し くなる。一方, Sekiyaら ${ }^{27}$ によると, 35M0.65 Te02 組 成近傍のガラス（MはZnあるいはBa）では，そのラマン スペクトルの比較から、テルル一酸素多面体からなる 連続網目構造はBa0系のガラスにおいてより多く切断さ れていると考えられる。これらの観点からすれば， $\mathrm{Ba}$ 0含有量の多いテルライトガラスほどガラス網目骨格の 柔軟性は大きいか，あるいは $\mathrm{BaO}-\mathrm{TeO}_{2}$ 系と $\mathrm{ZnO} 0-\mathrm{Te}_{2}$ 系 において網目骨格の采軟性はほとんど变わらないと考 えることができる.ところが，Fig.3に示すように，ガ ラス転移温度はBa0のZnOによる置換が進むにつれて低 くなっている.すなわち，BaOのZnoによる置換により， ガラス構造の柔軟性は増加すると考えられる。これは, 網目修飾酸化物の濃度が大きくなると，ガラス構造の 柔軟性はガラス網目骨格の柔軟性のみならず，網目修 飾イオンの局所構造の影響も受けることを表している. おそらく， $\mathrm{Zn}^{2+}$ と $\mathrm{Ba}^{2+}$ のイオン半径の違いや配位数の 違いがこのような差をもたらしているものと思われる。 ガラス構造の柔軟性が高ければ, 外部からの電場の印 加に対して, 構造単位の再配列, すなわち, 永久電気 双極子を有する三方両錐および三方錐の再配列は容易 に起こると考えられる．したがって，ZnO-Ba0-Te02系 ガラスではBaOのZn0による置換によむない第二高調波 強度および 2 次非線形光学定数が増加したと推测され る.また,Fig.1，Fig.2におけるポーリングの温度は $280^{\circ} \mathrm{C}$ であり，Fig. 3に示されたガラス転移温度に近い. したがって, ポーリングの際にガラスの構造緩和が起 こり,それがテルライトガラス構造単位の再配列を引 き起こすことは十分に考えられる。

ところで, 著者らは先に，Ba- $\mathrm{TeO}_{2}$ 系ガラスにおい て第二高調波の発生が見られない原因を, 外部電場に より $\mathrm{Ba}^{2+}$ の電子分極が優先的に起こるためであると考 えた ${ }^{20}$. 電子分極は緩和時間が短いため, 試料を室温 
に冷却後外部電場を取り除いたあとすぐ緩和が起こり， 永久双極子の凍結には到らない。一方，上述の結果よ り，Ba0の導入によるガラス構造の柔軟性の低下む，第 二高調波強度を下げる原因となりうる。どちらが主た る原因であるかは現時点では不明であるが， $\mathrm{Ba}^{2+}$ 以外 の電子分極の大きな陽イオンを含むテルライトガラス の 2 次非線形光学效果に関して考察することは意味が あると思われる。そこで本研究では $15 \mathrm{PbO} 085 \mathrm{Te}_{2}$ ガラ スを作製し，ポーリングを施したのちに第二高調波の 測定を行った。得られた第二高調波強度を，これまで に調べられた他の系のテルライトガラスの結果ととも にTable 1に示す。この表に示された第二高調波強度は 相対的な值である. Table 1より，電子分極の大きな $\mathrm{Pb}^{2+}, \mathrm{Ba}^{2+}$ 含むテルライトガラスでは第二高調波強 度はきわめて小さくなっていることが分かる。これら のガラスでは $\mathrm{Pb}^{2+} \mathrm{Ba}^{2+}$ の電子分極のためテルライト ガラス構造単位の配问が妨げられていると考えられる。 一方，Li+を含むガラスの第二高調波強度む比較的小さ い.このガラスでは外部電場に対して $\mathrm{Li}^{+}{ }^{+}$が容易に移動 し得る10、11.したがって，Li+の移動にとむなって誘 起される電気双極子がテルライトガラス構造単位の配 向に優先する． $\mathrm{Li}^{+}$は室温です比較的易動度が大きいの で゚・11， $\mathrm{Li}^{+}$に上る電気双極子は室温においては凍結 されない。この結果，第二高調波強度が小さくなる。 これらに対して, ZnO-TeO $0_{2}$ 系, $\mathrm{Nb}_{2} \mathrm{O}_{5}-\mathrm{TeO}_{2}$ 系, $\mathrm{HO}_{3}-\mathrm{Te}$ $\mathrm{O}_{2}$ 系では，組成に応じて值が変化するものの，第二高 調波強度が比較的大きい，以上のことから，電子分極 が小さく，イオン伝導への寄与が少ない陽イオンを含 むテルライトガラスにおいて，大きな第二高調波強度 が得られると期待される。

\section{4 結論}

電気的なポーリングを施すことによって光第二高調 波発生が見られることの知られているZn0-Ba0- $\mathrm{Te}_{2}$ 系 ガラスのガラス構造の柔軟性を知る目的で，この系の ガラスのガラス転移温度を測定し，第二高調波強度お よび 2 次非線形光学定数との関係を考察した. $\mathrm{TeO}_{2}$ 含 有量を一定とし，Ba0をZnoで置換するにつれて，ガラ 又転移温度は低下した。このことはZn0含有量の增加に ともないガラス構造の柔軟性が増加したことを示唆し， 構造の柔軟性に富んだガラスにおいて，電気双極子を 有する $\mathrm{Te} 0$ 、三方両錐および $\mathrm{Te}_{3}$ 三方雓の長距離秩序配 向が起こり易いと仮定することで，第二高調波強度の 組成依存性を定性的に説明した。また，Ba0含有量の多
い組成のガラスおよび $\mathrm{Pb} 0-\mathrm{Te}_{2}$ 系のガラスでは，第二 高調波発生は観察されないか，観察されてもその強度 はきわめて小さいものであった。これらのガラスでは 外部電場により $\mathrm{Ba}^{2+} \mathrm{Pb}^{2+}$ の電子分極が優先的に起こ り，テルライトガラス構造単位の配向分極が起こりに くくなっていると考え，られ，ガラスの柔軟性に加えて， 陽イオンの分極率が、テルライトガラスの第二高調波 強度に影響をおよばす因子であると推測される。

\section{参考文献}

1) J.E. Stanworth: Nature, 169 (1952) 581.

2) P. T. Sarjeant and R. Roy: J. Am. Ceram. Soc., 50 (1967) 500.

3) T. Yoko, K. Kamiya, H. Yamada and K. Tanaka: J. Am. Ceram. Soc., 71 (1988) C-70.

4) T. Yoko, K. Kamiya, K. Tanaka, H. Yamada and S. Sakka: J. Ceram. Soc. Jpn., 97 (1989) 289.

5) N. Mochida, K. Takahashi, K. Nakato and S. Shibusawa: J. Ceram. Soc. Jpn., 86 (1978) 317.

6) H. Binczycka, 0. Gzowski, L.Murawski and J.Sawicki: Phys. Stat. Sol. (a), 70 (1982) 51.

7) V.K. Dhawan, A.Mansingh and M. Sayer: J. Non-Cryst. Solids, 51 (1982) 87.

8) L.Murawski: J. Mater. Sci., 17 (1982) 2155.

9) K. Tanaka, T. Yoko, M. Nakano, M. Nakamura and K. Kamiya: J. Non-Cryst. Solids, 125 (1990) 264.

10) K. Tanaka, T. Yoko, H. Yamada and K. Kamiya: J. Non-Cryst. Solids, 103 (1988) 250.

11) K. Tanaka, T. Yoko, K. Kamiya, H. Yamada and S. Sakka: J. Non-Cryst. Solids, 135 (1991) 211.

12) S. Rossignol, J. M. Reau, B. Tanguy, J. J. Videau and J.Portier: J. Non-Cryst. Solids, 155 (1993) 77.

13) H. Burger, W. Vogel and V. Kozhukharov: Infrared Phys., 25 (1985) 395.

14) H. Nasu, O. Matsushita, K. Kamiya, H. Kobayashi and K. Kubodera: J. Non-Cryst. Solids, 124 (1990) 275.

15) S. -H. Kim, T. Yoko and S. Sakka: J. Am. Ceram. Soc., 76 (1993) 2486. 
16) K. Tanaka, K. Kashima, K. Hi rao, N. Soga, A. Mi to and H. Nasu: Jpn. J. Appl. Phys., 32 (1993) L843.

17) U. Osterberg and W. Margulis: Opt. Lett., 11 (1986) 516.

18) R. A. Myers, N. Mukherjee and S.R. J. Brueck: 0pt. Lett., 16 (1991) 1732.

19) K. Tanaka, K. Kashima, K. Hirao, N. Soga, A. Mi to and H. Nasu: J. Non-Cryst. Solids, submitted.

20) K. Tanaka, K. Kashima, K. Kajihara, K. Hi rao, N. Soga, A.Mi to and H. Nasu: SPIE Proceedings, 2289, Doped Fiber Devices and Systems, in press.

21) K. D. Singer, M. G. Kuzyk and J.E. Sohn: J. Opt.
Soc. Am., 4 (1987) 968.

22) D.A.Kleinman: Phys. Rev., 126 (1962) 1977.

23) P.D. Maker, R.W. Terhune, M. Nisenoff and C.M. Savage: Phys. Rev. Lett., 8 (1962) 21.

24) J. Jerphagnon and S.K.Kurtz: J. Appl. Phys., 41 (1970) 1667.

25) 尾坂明義, 邱建栄, 藤并達生, 難波徳郎, 高田潤, 三浦嘉也：材料，42（1993） 473 .

26) H. Burger, K. Kneipp, H. Hobert, W. Vogel, V. Kozhukharov and S. Neov: J. Non-Cryst. Solids, 151 (1992) 134.

27) T. Sekiya, N. Mochida and A. Oht suka: J. Non-Cryst. Solids, 168 (1994) 106. 